\title{
Application of E-Management and its Obstacles from Perspectives of Faculty Members at Imam Abdulrahman bin Faisal University
}

\author{
Reema Mahmoud Abod AlOqlah \\ Assistant Professor, Self- Department, \\ Deanship of the Preparatory Year and Supporting Studies, \\ Imam Abdurrahman AlFaisal University, Dammam, \\ P.O. Box: 1982, Dammam 34212, Saudi Arabia
}

DOI: https://doi.org/10.36941/jesr-2021-0067

\begin{abstract}
E-Management is very important in the current high-tech word, and it plays a vital role in the world's progress in general and academic field in particular. This study aimed to determine the degree of application of electronic management at Imam Abdul Rahman bin Faisal University and to identify the obstacles facing its application. The overall sample participated in this study was 285. A quantitative research design was employed in this study in which an adapted questionnaire was administered to the participants of this study. The sample includes faculty members from Imam Abdulrahman bin Faisal University. The results showed that the E-Management is reasonable applied at the university. Also, the results revealed that the organizational obstacles are insignificant, in addition, that the human obstacle is the most important obstacle among other obstacles, followed by the technical and financial obstacles, while the organizational obstacles came in the last rank. Some recommendations were provided based on the results of the present study.
\end{abstract}

Keywords: E-Management, Organizational obstacles, Technical and financial obstacles, Teaching, Human obstacles

\section{Introduction}

Electronic management or E-Management indicates a variety of systematic that aim to turn conventional office which depends on paper processes to paperless office depending on electronic processes (Radu \& Pólkowski, 2014). Technology is growing exponentially worldwide that driving an uprising in information and communication technology (ICT) (Osakede et al., 2017). In light of this scientific progress and emergence of digital or electronic technology, countries of the world imperative to move towards benefiting from this technology in all fields, including administrative field (Ellatif \& Ahmed, 2013). According to Royal Decree which included setting up a plan to provide government services and transactions electronically by the Ministry of Communications and Information Technology instead of traditional means, Kingdom of Saudi Arabia seeks to apply electronic management in all dealings in a number of governmental and private institutions to get rid of conventional management in order smoothing path for modern forms of interactivity (AL-asmari, 2010). E-management is gaining importance in administrative development as being a tool to facilitate and simplify administrative procedures, increase the productivity of workers, assist in decision-making, and activate the supervision process (Ellatif \& Ahmed, 2013). This importance was reflected in the 
educational administration and higher institutions in many outputs such as increasing arrival to postsecondary learning, enhancing the availability of resources for education, and facilitating interaction among learners (Osakede et al., 2017). E-Management has become a key strategy in Saudi tertiary institutions that provide a cost-accessible effective and scalable learning environment for rapid growth (Shakkah \& AlGamdi, 2015; Al-Jarrah, 2018). It is logical that universities administrators keep pace with what the ministry offer, so they employ electronic services to accomplish their work easily and simplify (Ikenna, 2015). Hajaia and Roud (2014) mentioned that E-management is a means to achieve the absolute and continuous satisfaction of the beneficiaries; this is done by providing educational services that exceed their expectations, characterized by simplification of performance and speed of achievement, and obtaining the service with minimal effort at any time and directly without the need to come to university. As a result of that, the administrators in universities are required to use modern administrative approaches in their work especially E-Management due to the growing demand for rapid completion of administrative work, and facilitating communication between workers inside the universities and between the university administration and the external community.

In spite of the efforts made in this field, the applications of E-Management in universities administration are still below the desired level, Ellatif and Ahmed (2013) mentioned that there are limitations of application of E-Management in the Arab environment. Also, Shakkah and AlGamdi (2015) pointed out that employees in universities need to raise their awareness about E-management and employ it in their work. Therefore, this study seeks to identify the reality of E-management applications at Imam Abdulrahman Bin Faisal University.

\section{Literature Review}

The insertion of information and communication technology (ICT) is a real revolution in management due to the change it brings about in the style of administrative work, effectiveness, and performance (Waswas \& Jwaifell, 2019). Hence the need for E-management, which means: moving from traditional work to informational applications including computer networks to link organizational units with each other to facilitate access to data and information to make appropriate decisions and complete work, and to provide services to beneficiaries efficiently at the lowest cost and in the fastest time possible (Osakede et al., 2017).

\subsection{Concept of E-Management}

E-Management in education is considered a new type of educational management types that has broad effects on educational institutions and their fields of work, strategies, and functions. These effects are not only due to the technological dimension represented by digital technologies but also to the administrative dimension represented by the development of administrative concepts that Accumulated for many decades, it is working to achieve more administrative flexibility in delegation and administrative empowerment (Bataineh, 2017).

There are a variety of E-Management definitions. Dayni (2010) defined E-Management as the ability to use ICT and new techniques to carry out administrative tasks electronically through the internet and networks of the automated computer. Ogbonna, Eze and Nkemdirim (2011) defined EManagement as diversity of services focused on electronic information with strengthening of the participatory components in order to accomplish the goals of administrative management. Badawi (2013) asserts that E-Management is a highly connected, competitive, advanced, and interactive productivity system that extends the boundaries of an organization to encompass the whole world. EManagement is seen as a more collaborative form of administration, with more coordination with external parties in policy-making and service delivery, and more collaboration within the workplace and university stakeholders (Younis, 2016; Osakede et al., 2017). 


\section{$2.2 \quad$ E-Management Importance}

The importance of E-Management stems from the importance of management in general, as it is the main driver of the efforts of workers in any institution due to its ability to contribute to the completion of administrative work accurately and quickly as well as the ease of communication between workers within the institution, and between the institution and the beneficiaries of the services it provides (Hajaia \& Roud, 2014; Osakede et al., 2017). Abu Ashour and AlNemri (2013) mentioned that there is a lot of importance of modern information systems, namely:

- Technologies and information systems are considered to be an important method for minimizing the cost.

- Sharing in innovation to establish a sophisticated method to create new services.

- Evolve services of customers by meeting specifications in the shortest time thinkable.

- Decrease the effort and time required to complete the procedures because of the simplicity of information retrieval.

At the same time, Osakede et al. (2017) indicated that the value of management information centered on raised accessibility, inclusiveness, and versatility in the delivery of services and quality services to be delivered by lower-cost alternatives. Based on Bataineh (2017) and Waswas and Jwaifell (2019) the importance of E-management is in:

- The capacity to manage immense quantities of information.

- The capacity to deal with large numbers of beneficiaries and users.

- Confrontation and managing the increase in information.

- The need for constant contact between employees in the work field.

- The direction towards taking advantage of technological advances and relying on information for decision-making.

From another aspect, Abdulrahman and Omar (2018) argue that E-management has several drawbacks that would limit its efficacy which are:

- Loss of safety and electronic eavesdropping.

- Paralysis of management in case of any defect.

In general, E-Management seeks to make good and effective improvements in contemporary educational organizations and institutions.

\subsection{E-Management application requirements}

The success of E-Management is related to the necessity to provide a set of necessary requirements, including human, financial, organizational, and software requirements. In addition, an integrated picture and an accurate and comprehensive assessment of the reality must be formed in terms of the availability of information technology, the appropriate infrastructure, human resources, and the necessary financial support, to make the most of these technical revolutions (Bataineh, 2017). Abdulrahman and Omar (2018) defined several significant criteria for the application of E-Management in universities, which could be summed up as follows:

- The devotion of top management to promoting and implementing E-Management initiatives.

- Strategic preparation for the digital transformation.

- Creation of an integrated strategy between all quarters for comprehensive contact.

- Emphasis on researching and meeting customer requirements.

- Concern for staff that have provided facilities for E-Management.

- Concentrate on technical skills.

These requirements for implementing E-Management systems represent ambitious work programs to place universities at the heart of the information revolution as well as integration into the digital world, and in the event of a lack of availability of these requirements or some of them, universities will face many obstacles and challenges that prevent applied. 


\subsection{Obstacles Facing Implementing E-Management}

Over the years, researchers have uncovered numerous obstacles to implementation of E-Management. Hajaia and Roud (2014) and Bataineh (2017) classified those obstacles by taking a look at follows classifications:

- Organizational obstacles: This concerns the essence of the organization structure and the absence of electronic transaction systems and laws and the central management of the organization and others.

- Technical and financial obstacles: Including the absence of laboraties readiness for implementation, slow and weak services of internet and inadequate protection to safeguard the users from network penetration, recurrent regulations breakdowns, the absence of financial resources and maintenance, the high expense of the internet and communications, computers and others.

- Human obstacles: include nature of humans, closed doors culture, lack of trust in the privacy and confidentiality of personal transactions and their security, absence of incentives for members of the faculty staff, and poor English language proficiency among some faculty members.

E-Management is an integrated system that will not work efficiently and achieve the goals of its use except when all the elements and requirements for their application are complete, and on top of these requirements are the provision of integrated infrastructure, training of workers, and the provision of appropriate application programs.

\subsection{Previous Studies}

This study reviewed related E-Management studies and research and degree of its implementation and its obstacles including the study of Hajaia and Roud (2014) that objectives to determine the obstacles of applying E-Management at Tafila technical university from the faculty staff members' perspectives. The study sample consisted of (130) faculty staff members. The findings showed that human obstacles were in the first rank, followed by financial obstacles and technical obstacles respectively, while organizational obstacles were in the last rank. However, all the obstacles were of a high degree. The study by Abu Ashour and AlNemri (2013), aimed to investigate the level of applying E- Management at Yarmouk University in Jordan, the sample consisted of (647) out of which (320) educational board members and (327) administrators randomly selected from the administration pool. The results showed that the application of the electronic management was high from the perspective of the educational board members. The study of Bishri (2011) aimed to detect the application of EManagement in the department of Umm Al Qura University in Mecca from the perspectives of administrators and the faculty staff members at the university. The study sample consisted of (441) administrators and faculty staff members. The most prominent results were the impediments relating to English language skills weakness, financial impediments, and that the degree of using EManagement was moderate. Kassab (2011) conducted a study aimed to detect the relationship between organizational variables and the application of E- Management in Palestinian universities. The sample consisted of (161) faculty staff members. The results indicated that there is a lack in legislation and laws needed for applying E- Management as well as a lack of employee training for applying E- Management. Al-Jarrah (2018) identified the degree of applying E- Management in Departments of the Ministry of Education in Jordan. The study sample consisted of (307) employees of administrative staff in the centre of the Jordanian Educational Ministry. The most important finding of the study is that the degree of EManagement was high. Study of Waswas and Jwaifell (2019) aimed at identifying the level of applying E-management at Al-Hussein Bin Talal University in Jordan. The study sample consisted of (249) administration members at Al-Hussein Bin Talal University. The results showed that the level of applying E-management at Al-Hussein Bin Talal University is average with regard to administrative and technical dimensions, while it is poor regarding the materialistic dimension. 


\section{Research Questions}

The researcher hopes that this study will fill the shortage in areas related to E-management in institutions educational, especially at Saudi Universities. This study aims to detect the degree of application E-Management and the obstacles that limit its application in Imam Abdulrahman bin Faisal University by answering the following questions:

1. What is the degree of E-Management application in Imam Abdulrahman bin Faisal University from a point of view of faculty members?

2. What are the obstacles facing the application of E-Management in Imam Abdulrahman bin Faisal University from a point of view of faculty members?

\section{Methodology}

In this study, descriptive survey design and quantitative approach have been used to a careful, factual, and systematic description of the facts and characteristics of a population. Sugiyono (2012) identified quantitative descriptive research as research in which all members of the research population or a large sample of it are questioned, with the aim of describing the phenomenon studied in terms of its nature and degree of existence only, without going beyond that to study the relationship or deduce the reasons.

\subsection{Participants}

The study participants consisted of all faculty members in Imam Abdulrahman bin Faisal University a number (3248) faculty members according to the annual statistical report of the Saudi Ministry of Education (2017/2018). The researcher sampled (346) faculty members based on the suggestion of Morgan's table for determining sample size. To the selection of faculty members at the universities previously listed, the simple random sampling technique was used. (305) questionnaires out of (346) were returned, (20) questionnaires were excluded due to the non-completion of the answers by the respondents, thus making the number of questionnaires valid for analysis (285) questionnaires.

\subsection{Instrument}

In this study, questionnaires were adopted to faculty members to measure their perspectives on each item in the questionnaire by Likert Scale includes five-point from " 1 " (very low) to " 5 " (very high). The questionnaire was broken down into 3 parts. Part (1) gathers background information of the respondents, such as 'Sex, Academic rank, The College, Years of experience'. Part (2) consisted of 24 questions prepared to measures the degree of E-Management applying. The questions for this part were adopted based on studies by Bataineh (2017); Al-Jarrah (2018) and Waswas and Jwaifell (2019). Part (3) consisted of 33 questions prepared to measures obstacles facing the application of E-Management. The questions for this part were adopted based on studies by Hajaia and Roud (2014) and Shakkah and AlGamdi (2015).

\subsection{Data Analysis Procedures}

The researcher analyzed the data quantitatively using a set of statistical methods to reach an answer to the study questions, SPSS program was used to calculate Cronbach's alpha coefficient to measure the reliability of items and to extract the frequencies, percentages, means, and standard deviations of the respondents' answers about applications E-Management in Imam Abdulrahman bin Faisal University and obstacles facing its application. To verify the validity of the instrument, the researcher was presented the instrument to (7) experts from the faculty members of Saudi universities who hold a doctorate in education and administrative sciences to ensure linguistic formulation, scientific accuracy, 
and clarity. In light of the comments of these experts, the number of questions of the degree of application E-Management became (17 questions); in regards to obstacles facing the application of EManagement, the number of questions became (30 questions).

\section{Findings}

Cronbach alpha was used to test the respondents' internal accuracy and their responses. The value that has $(60 \%)$ or more, showed the reliability in responses of respondents (Bryman \& Bell, 2011), as shown in Table 1.

Table 1. Cronbach Alpha Test

\begin{tabular}{lc}
\hline Variables/Dimensions & Cronbach Alpha Value \\
\hline Degree of E-Management Applying & 0.865 \\
\hline Organizational Obstacles & 0.861 \\
\hline Technical and financial obstacles & 0.822 \\
\hline Human Obstacles & 0.866 \\
\hline Obstacles Style as Whole & 0.821 \\
\hline
\end{tabular}

Table (1) showed that the values of the internal consistency coefficient for the dimensions of the study were high and ranged between (o.821-0.866). This means that the value of the Cronbach Alpha coefficient for all parts of the questionnaire is higher than (o.6o). This indicates that the study instrument has internal consistency between items.

The descriptive analysis was employed to describe the respondents' profile in terms of "Sex, Academic rank, The College, Years of experience". The majority of respondents were female representing $67.0 \%$, while $33.0 \%$ were male, respectively, as shown in Table 2 . With respect to the academic rank of respondents, $76.5 \%$ of respondents are assistant professors. While $17.2 \%$ of respondents are associate professors and $6.3 \%$ were full professors. With regard to the College, table 2 shows that the overwhelming majority working in humanities colleges with a rate of $63.9 \%$, the respondents who work in scientific colleges representing $36.1 \%$ out of a total of respondents. With respect to the work experience, the results showed that the majority of the respondents have 5 to 10 years of experience representing $64.6 \%$, followed by the respondents who have less than 5 years of experience representing $20.7 \%$. Finally, the respondents have more than 10 years' experience representing $14 \cdot 7 \%$.

Table 2. The Respondent Profile $(\mathrm{N}=\mathbf{2 8 5})$

\begin{tabular}{llcc}
\hline Variables & Category & $\mathbf{N}$ & $\mathbf{\%}$ \\
\hline Gender & Male & 94 & 33.0 \\
& Female & 191 & 67.0 \\
\hline Academic rank & Assistant professors & 218 & 76.5 \\
& Associate professors & 49 & 17.2 \\
& Full professors & 18 & 6.3 \\
The College & Humanities & 182 & 63.9 \\
& Scientific & 103 & 36.1 \\
\hline \multirow{2}{*}{ Experience } & Less than 5 years & 59 & 20.7 \\
& 5-10 years & 184 & 64.6 \\
& More than 10 years & 42 & 14.7 \\
\hline
\end{tabular}

\subsection{Research Question 1}

In order to answer the first question of the study, the researcher used arithmetic means and standard 
deviation for each item of measures degree E-Management application. In order to interpret the results, arithmetic averages were adopted based on the Table mentioned below.

Table 3. Interpretation of arithmetic means of Respondents' Answer for Each Item

\begin{tabular}{cc}
\hline Mean & Information \\
\hline $1,00-1,79$ & Strongly Disagree (SD) \\
\hline $1,80-2,59$ & Disagree (DA) \\
\hline $2,60-3,39$ & Moderate Agree (MA) \\
\hline $3,40-4,19$ & Agree (A) \\
\hline $4,20-5,00$ & Strongly agree (SA) \\
\hline
\end{tabular}

Source: (Bryman \& Bell, 2011).

Table 4. Arithmetic means and standard deviation for each item and for degree E-Management application as a whole

\begin{tabular}{|c|c|c|c|}
\hline $\mathbf{N}$ Item & Mean & St.dev & Inf. \\
\hline 1 Faculty members obtain accurate information about the university electronically & 3.74 & 1.17 & A \\
\hline 2 The university communicates with the Education Office electronically & 3.45 & 1.34 & A \\
\hline 3 Communication between faculty and administrators takes place electronically & 3.24 & 1.36 & MA \\
\hline 4 Faculty members make use of electronic information to treat students' problems & 3.30 & 1.33 & MA \\
\hline 5 The faculty members complete the leave procedures of all kinds electronically & 3.19 & 1.42 & MA \\
\hline $\begin{array}{l}6 \text { Faculty members obtain (schedule - student names - information about students) } \\
\text { electronically }\end{array}$ & 3.58 & 1.39 & A \\
\hline 7 Faculty members can learn about their job performance level electronically & 3.83 & 1.16 & A \\
\hline 8 The student can obtain the academic schedule through the university's website & 3.87 & 1.12 & A \\
\hline $\begin{array}{l}\text { The admission and registration procedures for students can be completed through the } \\
\text { university's website }\end{array}$ & 3.71 & 1.32 & A \\
\hline $\begin{array}{l}\text { Faculty members offer the student various enrichment programs through the university's } \\
\text { website }\end{array}$ & 3.40 & 1.18 & A \\
\hline 11 faculty members and students can submit their data electronically & 3.46 & 1.27 & A \\
\hline $\begin{array}{l}\text { The e-mail in its current status is sufficient for communication between the university and } \\
\text { the Ministry of Education }\end{array}$ & 3.49 & 1.20 & A \\
\hline 13 Electronic information is available on the faculty, staff, and students & 4.45 & .973 & SA \\
\hline $\begin{array}{l}\text { Electronic information is available that includes the university's equipped (equipment - } \\
\text { library - building) }\end{array}$ & 3.12 & 1.29 & MA \\
\hline 15 The university's electronic data is constantly checked and validated & 3.57 & 1.39 & A \\
\hline $\begin{array}{l}16 \text { The top management provides electronically the information needed to prepare the annual } \\
\text { plan for faculty members }\end{array}$ & 3.05 & 1.40 & MA \\
\hline $\begin{array}{l}17 \text { An electronic report (daily - monthly - quarterly - yearly) can be prepared on the progress } \\
\text { of academic work }\end{array}$ & 3.27 & 1.45 & MA \\
\hline $\begin{array}{lll}\text { Total } & 3.51 & .724 \\
\end{array}$ & & & \\
\hline
\end{tabular}

Table 4 showed that the mean value of degree E-Management application was (3.51) with a standard deviation of (o.724). This means that the E-Management from the point of view of faculty members at Imam Abdulrahman bin Faisal University was applied agreeably. Item 13 got on highest means among items of applying E-Management which states, "Electronic information is available on the faculty, staff, and students", with (4.45). Also, item 8, which states, "The student can obtain the academic schedule through the university's website"; and item 7 , which states, "Faculty members can learn about their job performance level electronically" have the high means value among the items of the E-Management application (3.87) and (3.83) respectively. While item 16, which states, "The top management provides electronically the information needed to prepare the annual plan for faculty members"; item 14, which 
states "Electronic information is available that includes the university's equipped (equipment - library - building)" and item 5, which states "The faculty members complete the leave procedures of all kinds electronically" have lowest value of the means among the items with 3.05, 3.12 and 3.19 respectively. This result is consistent with the study by Abu Ashour and AlNemri (2013) and Al-Jarrah (2018). While this result differed with the study of Bishri (2011); Kassab (2011) and Waswas and Jwaifell (2019) that revealed that the level of applying E-management was moderate.

The researcher believes that University official's awareness about the necessity of facilitating access to information, facilitating its organization, facilitating its preservation, reducing paper use, facilitating business follow-up, and provide many opportunities and advantages for both the contemporary organization and the modern society are the main reason to applying E-Management at Imam Abdulrahman bin Faisal University.

\subsection{Research Question 2}

In order to answer the second question of the study, the researcher used arithmetic means and standard deviation for each item of measure to obstacles facing the application of E-Management.

Table 5. Arithmetic means and standard deviation for each item and for each dimension of the obstacles

\begin{tabular}{|c|c|c|c|c|}
\hline \multirow{2}{*}{\multicolumn{5}{|c|}{\begin{tabular}{|c|}
$\mathrm{N}$ Item \\
Organizational obstacles
\end{tabular}}} \\
\hline & & & & \\
\hline 1 & Lack of correct preparation for the process of transition to E-Management & 2.86 & 1.39 & MA \\
\hline 2 & Lack of the required legislation necessary for E-Management to be enforced. & 2.81 & 1.35 & $\mathrm{MA}$ \\
\hline 3 & Lack of awareness of the value of applying E-Management & 2.76 & 1.35 & $\mathrm{MA}$ \\
\hline 4 & Lack cooperation between the university's administrative centres. & 2.89 & 1.40 & $\mathrm{MA}$ \\
\hline 5 & Centralization of the university's departments. & 3.01 & 1.27 & $\mathrm{MA}$ \\
\hline 6 & Routine administrative processes by university departments & 2.94 & 1.36 & $\mathrm{MA}$ \\
\hline 7 & The Presidency's sluggish response to the demands for change & 2.96 & 1.32 & $\mathrm{MA}$ \\
\hline 8 & Vagueness of the future vision for the application of E-Management & 2.85 & 1.34 & $\mathrm{MA}$ \\
\hline Total & & 2.89 & 0.922 & MA \\
\hline \multicolumn{5}{|c|}{ Human obstacles } \\
\hline 9 & Some workers' poor English language skills & 3.46 & 1.21 & A \\
\hline 10 & Departments and deans worry about increased administrative duties & 3.93 & 1.08 & A \\
\hline 11 & Employees worry about losing or hacking any of the information & 3.99 & 1.02 & A \\
\hline 12 & $\begin{array}{l}\text { Poor acceptance for the concept of electronic administration from some employees for fear of losing } \\
\text { their position careers }\end{array}$ & 3.85 & 1.22 & A \\
\hline 13 & lack training and preparation of staff in the use of electronic technologies & 3.82 & 1.22 & A \\
\hline 14 & Lack of specialized employees in the maintenance of automated computers & 3.62 & 1.19 & A \\
\hline 15 & Lack of specialized personnel in the electronic administration in the university & 3.55 & 1.30 & $\mathrm{~A}$ \\
\hline Total & & 3.75 & 0.88 & $\mathbf{A}$ \\
\hline \multicolumn{5}{|c|}{ Technical and financial obstacles } \\
\hline 16 & Poor support for electronic devices in technical terms & 2.95 & 1.36 & MA \\
\hline 17 & Poor of integrated and accurate databases & 3.02 & 1.43 & $\mathrm{MA}$ \\
\hline 18 & The weak level of infrastructure required for electronic administration applications & 2.40 & 1.27 & $\mathrm{MA}$ \\
\hline 19 & Poor University contact service & 3.19 & 1.43 & $\mathrm{MA}$ \\
\hline 20 & Lack of a protection mechanism to safeguard a database relating to university transactions & 3.05 & 1.37 & MA \\
\hline 21 & University laboratory design is not suitable for the application of E-Management. & 2.95 & 1.41 & $\mathrm{MA}$ \\
\hline 22 & Lack of necessary initiatives that provide directions for the application of E-Management. & 3.20 & 1.40 & MA \\
\hline 23 & Poor electronic link between the deans and departments of the university. & 3.44 & 1.31 & A \\
\hline 24 & Ease of internet hacking at university & 3.15 & 1.44 & $\mathrm{MA}$ \\
\hline 25 & Insufficient university computers proficiency & 3.14 & 1.43 & $\mathrm{MA}$ \\
\hline 26 & The dearth of financial rewards in the field of electronic work for distinguished employees & 2.74 & 1.35 & $\mathrm{MA}$ \\
\hline 27 & Weak allocated budget for the acquisition of security information systems & 3.04 & 1.38 & $\mathrm{MA}$ \\
\hline 28 & High prices for certain electronic devices and applications & 3.22 & 1.45 & MA \\
\hline 29 & Poor financial support to studies and research in the area of information technology & 3.47 & 1.15 & A \\
\hline 30 & Weak allocated of the budget for the creation of programs and automated computer applications & 3.44 & 1.27 & A \\
\hline Total & & 3.09 & 0.71 & MA \\
\hline All di & mensions & 3.19 & 0.53 & MA \\
\hline
\end{tabular}


Table 5 showed that the mean value of the organizational obstacles was (2.89) with a standard deviation of (0.92). This means that the organizational obstacles from the point of view of faculty members at Imam Abdulrahman bin Faisal University are insignificant. Item 5, which states, "Centralization of the university's departments"; and item 7, which states, "The Presidency's sluggish response to the demands for change" have the highest means value among the items of the organizational obstacles with (3.01) and (2.96) respectively. While item 3, which states, "Lack of awareness of the value of applying E-Management"; item 2, which states "Lack of the required legislation necessary for EManagement to be enforced" and item 8, which states, "Vagueness of the future vision for the application of E-Management" have lowest value of the means among the items with (2.76), (2.81) and (2.85) respectively.

Also, Table 5 showed that the mean value of the human obstacles was (3.75) with a standard deviation of (o.88). This means that the human obstacles from the point of view of faculty members at Imam Abdulrahman bin Faisal are significant. Item 11, which states, "Employees worry about losing or hacking any of the information" and item 10, which states, "Departments and deans worry about increased administrative duties" have the highest means value among the items of the democratic leadership style with (3.99) and (3.93) respectively. While item 9, which states, "Some workers' poor English language skills"; item 15, which states, "Lack of specialized personnel in the electronic administration in the university" and item 14, which states "Lack of specialized employees in the maintenance of automated computers" have lowest value of the means among the items with (3.46), (3.55) and (3.62) respectively.

In addition, Table 5 shows that the mean value of the technical and financial obstacles was (3.09) with a standard deviation of (0.71). This means that the technical and financial obstacles from the point of view of faculty members at Imam Abdulrahman bin Faisal University are moderately significant. Item 29, which states, "Poor financial support to studies and research in the area of information technology"; and both item 30, 23 which states, "Weak allocated of the budget for the creation of programs and automated computer applications", "Poor electronic link between the deans and departments of the university" have the highest means value among the items of the technical and financial obstacles with (3.47) and (3.44) respectively. While item 18, which states, "The weak level of infrastructure required for electronic administration applications"; item 26, which states, "The dearth of financial rewards in the field of electronic work for distinguished employees" and item 16, 21, which states, "Poor support for electronic devices in technical terms", "University laboratory design is not suitable for the application of E-Management" have lowest value of the means among the items with (2.40), (2.74) and (2.95) respectively.

Evident from the above that the human obstacle at Imam Abdulrahman bin Faisal University is the most important obstacle among obstacles, followed by the technical and financial obstacles, while the organizational obstacles came in the third and last rank. The researcher believes that the reason for this result may be due to poor acceptance of the concept of electronic administration from some employees for fear of losing their position careers, and the lack of training and preparation of staff in the use of electronic technologies are most reasons that show the human obstacles as most important obstacle among obstacles for applying E-Management. These results are consistent with the study of Bishri (2011); Kassab (2011) and Hajaia and Roud (2014). While these results differed with these studies about the significance of obstacles on applying E-Management, where the results of these studies showed that the obstacles have moderately significant.

\section{Recommendations}

In light of the results reached in this study, the researcher came up with some recommendations that could contribute to the application of E-Management in Universities, and reduce its obstacles, as follows:

The first recommendation is: that the higher management (the Ministry of Education) put the appropriate procedural plans to implement electronic management in universities and inform the 
education personnel of those plans.

The second recommendation is: That the top management takes the initiative to train administrators and faculty members in practical training on E-Management applications.

The third recommendation is: providing universities with modern computers with advanced capabilities suitable for administration work.

The fourth recommendation is: establish an electronic network in universities to connect all university facilities electronically.

The fifth recommendation is: adoption of electronic signatures in transactions between higher administrations and university administrations.

\section{Conclusion}

This study aimed to determine the degree of E-Management application at Imam Abdulrahman bin Faisal University and its obstacles, and then come up with some proposals and recommendations to contribute to activating electronic applications in the management of Universities and to identify the most prominent obstacles, where the results showed that most of the E-Management applications in the administrations of Imam Abdul Rahman bin Faisal University were agreeably, and there are some obstacles that limit the application of E-Management in the university departments.

\section{References}

Abdulrahman, O., \& Omar, I. M. (2018). The Impact of Applying Electronic Management System on the English Language Level: A Case study at Cihan University. International Journal of Research and Engineering, 5(7).

Abu Ashour, K. and Nimri, D. (2013) 'The level of application of electronic administration at Yarmouk University from the point of view of the teaching staff and administrators', Jordanian Journal of Educational Sciences, 9(2), 199-220.

Al-Asmari, A. M. (2010). E-learning in Saudi Arabia: Past, present and future. Near and Middle Eastern Journal of Research in Education, $2010(1), 2$.

Al-Jarrah, H. Y. M. (2018). The degree of applying the electronic administration in Departments of Jordanian Educational Ministry. International Journal of Economics and Business Research, 15(4), 490-508.

Badawi, K.R.S. (2013). Effect of e-management on human performance, case study, unpublished master thesis, Port Said University. Port Said, Egypt

Bataineh, K. A. (2017). The impact of electronic management on the employees' performance field study on the public organizations and governance in Jerash governorate. Journal of Management and Strategy, 8(5), 86-10o.

Bishri,M.(2011). Obstacles for applying the Electronic administration in the departments of Umm Al-Qura University in Mecca from the perspective of female administrator and factually staff members at the University. Unpublished master Thesis, Umm Al-Qura University,Mecca- Saudi Arabia.

Dayni, R., K. W. (2010). Effect of e-management and role of HR development in Rafidain Bank on improvement of the organization performance, unpublished master thesis, Middle East University, Ammaan, Jordan.

Ellatif, H. A. A., \& Abdulmutalib, S. (2013). E-Management; configuration, functions and role in improving performance of Arab institutions and organization. International Journal of Computer Applications, 8o(6).

Hajaia, S., \& Roud, A. (2014). The obstacles of applying electronic administration in Tafila technical university (TTU) from the faculty staff members' perspectives. International Journal of Humanities and Social Science, 4(11), 205-213.

Kassab,V.(2011). The relationships between the variables and the application of regulatory electronic administration in Palestinian universities Gaza Strip, , Unpublished MA Thesis, Al-Azhar University, Gaza -Palestine.

Ogbonna, J. U., Eze, M. U., \& Nkemdirim, V. (2011). University Management Dynamics: Issues of e-Administration and the User Communities Perceptive in Nigeria. ABSU Journal of Environment, Science and Technology, 1424

Osakede, K. O., Ijimakinwa, S. O., Arijeniwa, W., Adesanya, T. O., \& Ojo, A. D. (2017). The Impact of EAdministration on Service Delivery in Adekunle Ajasin University Akungba-Akoko,(AAUA) Ondo State, Nigeria. Management Studies and Economic Systems, 54(5305), 1-10.

Radu, A. M., \& Pólkowski, Z. (2014). Theoretical, technical and practical aspects of e- administration. Zeszyty naukowe DWSPiT. Studia z Nauk Spotecznych. NR, 7 . 
Shakkah, M. S., \& AlGamdi, S. A. (2015). An Investigation for Electronic-Management Use in Educational Projects Management (A Case Study in AL Baha-KSA Area). American Journal of Economics and Business Administration, 8(1), 1-8.

Sugiyono, P. D. (2012). Metode Penelitian Kuantitatif, Kualitatif, dan R\&D. bandung: alfabeta.

Waswas, D., \& Jwaifell, M. (2019). The Role of Universities' Electronic Management in Achieving Organizational Excellence: Example of Al Hussein Bin Talal University. World Journal of Education, 9(3), 53-66.

Younis, M. (2016), The Transformation Towards Electronic Management Conference of the Development of the System of Pre-university Education Visions and Projects, Nasr, Egypt. 